\title{
Enhancing the Emotional Well-Being of Perinatally HIV-Infected Youth Across Global Contexts
}

\author{
Latoya Small • Micaela Mercado • Priya Gopalan • Gisselle Pardo • \\ Claude Ann Mellins • Mary McKernan McKay
}

Published online: 10 April 2014

(C) Springer International Publishing 2014

\begin{abstract}
Introduction Increased access to antiretroviral treatment worldwide makes it more possible for children diagnosed with HIV before their 15th birthday to age into adolescence and beyond. Many HIV+ youth navigate stressors including poverty and resource scarcity, which may converge to produce emotional distress. For over a decade, Collaborative HIV Prevention and Adolescent Mental Health Project (CHAMP) investigators partnered with youth, caregivers, providers, and community stakeholders to address the health, mental health, and risk-taking behaviors of perinatally HIV-infected youth. This paper explores the mental health needs of aging cohorts of HIV+ youth, across three global contexts, New York (USA), Buenos Aires (Argentina), and KwaZulu-Natal (South Africa), to inform the development and implementation of a combination of HIV care and prevention supports for HIV+ youth. Methods Analysis of data pooled across three countries involving HIV+ early adolescents and their caregivers over time (baseline and 3-month follow-up) was conducted. Univariate and multivariate analyses were applied to data from standardized measures used across sites to identify mental health needs of youth participants. The impact of the site-specific versions of
\end{abstract}

L. Small $(\bowtie) \cdot$ M. M. McKay

McSilver Institute for Poverty Policy and Research, Silver School of

Social Work, New York University, NY, USA

e-mail: latoya.small@nyu.edu

M. Mercado · P. Gopalan · G. Pardo

McSilver Institute for Poverty Policy and Research, New York

University, NY, USA

C. A. Mellins

HIV Center for Clinical and Behavioral Studies, Columbia

University Medical Center, NY, USA

C. A. Mellins

New York State Psychiatric Institute, NY, USA a family-strengthening intervention, CHAMP+ US, CHAMP+ Argentina, CHAMP+ SA, was also examined relative to a randomized standard of care (SOC) comparison condition. Results Analyses revealed mental health resilience in a large proportion of HIV + youth, particularly behavioral functioning and overall mental health. Yet, significant numbers of caregivers across country contexts reported impaired child emotional and prosocial well-being. Significant site differences emerged at baseline. Involvement in the CHAMP+ Family Program was related to significant improvement in emotional well-being and a trend towards enhanced prosocial behavior relative to SOC across global sites.

Conclusions Ongoing partnerships with youth, family, and provider stakeholders across global sites helped to tailor programs like CHAMP+ to specific contextual needs. This has global intervention research and care implications as cohorts of HIV+ children age into adolescence.

Keywords Mental health · Adolescents · HIV · South Africa • United States $\cdot$ Argentina $\cdot$ Behavioral health $\cdot$ Perinatally infected HIV youth · ART · Antiretroviral treatment . Well-being

\section{Introduction}

Prior to antiretroviral therapy (ART) becoming widely available to perinatally infected children, the vast majority died before adolescence (Chin 1990; Nicoll et al. 1994; New York City Department of Health and Mental Hygiene 2012; Mellins et al. 2009a; Newell et al. 2004). Fortunately, this dire situation has improved in important ways. First, with aggressive prenatal care efforts, mother-to-child transmissions have been reduced to approximately $3.5 \%$ in many country contexts (South Africa Medical Research Council: MRC 2011; Pan American Health Organization 2013; Tlale et al. 2008; 
World Health Organization 2011). Next, as ART became globally available in low- to middle-income countries (LMIC), hundreds of thousands of HIV+ children now have a greater likelihood of reaching adolescence and young adulthood. By 2012, there were 3.3 million children living with HIV who were diagnosed before their 15th birthday worldwide (UNAIDS 2013). A new set of challenges for the youth and the adults rearing them have emerged.

More specifically, these young people now must navigate the challenge of growing up with a chronic stigmatizing illness that requires intensive ongoing involvement with emerging HIV medical programs and consistent adherence to lifesaving medications. Further, as a result of the AIDS epidemic having particularly devastating consequences among populations highly impacted by poverty and poor access to health-related resources, HIV+ youth and their families too often must confront stressors related to economic deprivation and resource scarcity. Although across the globe, poverty presents context-specific challenges, its presence makes complying with HIV medical care that much more challenging as well as creates a set of underlying conditions that can fuel emerging health, mental health difficulties, and behavioral risk-taking among HIV+ youth.

The purpose of this paper is twofold. First, this study aims to identify the universal and specific mental health needs of perinatally infected youth across three global contexts: New York, USA; Buenos Aires, Argentina; and KwaZulu-Natal, South Africa. This comparison across country contexts presents a unique opportunity to explore similarities and differences as the sites included here differ substantially in terms of the size and scope of their respective exposure to and experience with the pediatric HIV epidemic, as well as the capacity to launch a medical response, including opportunities to access ART and provide care to children. More specifically, in 2010, an estimated 390,000 children were newly infected with HIV, the vast majority through vertical transmission and approximately 350,000 of them were living in South Africa, a LMIC. Estimates of perinatally infected children in Argentina, also a LMIC, are more difficult to determine given lack of country-specific surveillance data; however, WHO (2011) estimates that 42,000 (3,900 new infections) children are living with HIV in Latin America with Argentina and Brazil being significant contributors to this number based on population, HIV prevalence, and mother-to-child transmission rates (WHO 2011; Center for Disease Control and Prevention 2012; UNAIDS and WHO 2013; Central Intelligence 2011). Finally, there were 217 new pediatric infections in the USA (adding to 9,522 perinatally infected youth across the country).

The second purpose of this study is to examine outcomes associated with a contextually tailored family-strengthening approach to promote mental health outcomes in aging cohorts of HIV+ youth.
Historical and Contemporary Perspectives on Perinatal HIV Infection

Children born with HIV infection after 1995 have had significantly improved chances of AIDS-free survival compared with those born between 1989 and 1994. Youth born before 1995 were twice as likely to develop an AIDS-defining illness or die by their fifth birthday compared with children born recently (Chin 1990; Nicoll et al. 1994; NYC DOHMH 2012).

Across North and South America, as well as Africa, as chances for survival increased, HIV-positive youth inevitably began to experience the developmental transition into adolescence with issues related to puberty, growth, peer relations, and sexuality emerging. However, these typical developmental challenges were also shaped by issues related to HIV-related stigma, transmission risk, and the increasing awareness of and responsibility for managing a chronic disease that was likely considered terminal at the time of their diagnosis (Mellins and Malee 2013; McKay et al. 2007; Deeks et al. 2013).

Further, perinatally infected adolescents began to confront the continual need to incorporate frequent visits to health care providers and complex medication schedules into their daily lives, while simultaneously experiencing normative social pressures to "fit in" with peers (Wiener and Mellins 2010; Domek 2006). Moreover, across multiple countries and contexts, the majority of pHIV+ youth live in urban povertyimpacted communities which present stressors related to elevated rates of violence, drug use, as well as diminished youthsupportive resources (Gopalan et al. 2012). Further, many HIV+ adolescents are navigating their immediate context and developmental challenges while also confronting the additional strain of caring for or potentially losing their only parent to HIV. Risk of perinatal HIV transmission increases when mothers have poorer health (i.e., higher viral load); therefore, seropositive youths are at greater risk of having a mother die from illness and limited access to resources (Garcia et al. 1999). They are also likely to live with a caregiver other than the birth mother. These youth may have additional daily responsibilities, increased exposure to stigma, food insecurity, and bullying (Mellins et al. 2009a; Mellins and Malee 2013; Cluver et al. 2007; Cluver and Orkin 2009). Compounding factors put this vulnerable population of young people at high risk for poor behavioral and mental health outcomes (Wiener and Mellins 2010; Mellins et al. 2006; Pearlstein et al. 2013; Smith et al. 2006).

Pediatric HIV Care: Rollout of Lifesaving Medications

\section{USA}

While seropositive youth face common social barriers to their well-being across global contexts, the availability of pediatric ART medications differs substantially by site. Across all sites, 
the rollout of pediatric ART medications came years after adults. For example, while adults were prescribed AZT in the late 1980s, the medication was not approved for children until the 1990s (CDC 1994; FDA.gov). New York City has been an epicenter of the HIV epidemic in the USA (Abrams et al. 2011). Prior to 1996 in New York City, over $60 \%$ of youth diagnosed with HIV did not survive beyond adolescence (NYC DOHMH 2012). They lived in low-income communities of color with limited access to treatment (Abrams and Nicholas 1990; Kang et al. 2011; Cunningham et al. 1995). Substantial effort was directed towards increasing access to care which improved considerably over time (NYC DOHMH 2012). Given that ART was available in New York City earlier in the epidemic in comparison to other global contexts, the cohort of pHIV+ youth is aging rapidly with the first wave beginning to enter young adulthood (Elkington et al. 2011).

\section{Argentina}

Argentina's rollout of ART medication happened later than the experience of the USA, occurring in the late 1990s (Blanco et al. 1998). A decade ago, $41 \%$ of children in need of antiretroviral therapy actually received consistent care despite the commitment to universal health care in Argentina (WHO 2011). However, over time, Argentina has continued to steadily increase ART availability and now covers $79 \%$ of all in need (WHO 2011). Thus, as access to ARVs has increased, it has also resulted in a growing population of children who survive and must live with HIV disease as a chronic, stigmatizing, and transmittable illness (WHO 2011).

\section{South Africa}

The most recent rollout of HIV medications of the threecountry context focused on here has been in South Africa. In 2010, $70 \%$ of the world's new HIV infections were diagnosed in sub-Saharan Africa. Women children and young infants made up more than $60 \%$ of new HIV infections in 2006. This region has one of the highest rates of HIV-infected children in the world (UNAIDS 2010; South African Department of Health: SADOH 2003; WHO 2007). Estimates suggest that approximately 350,000 children have been born HIV+ in South Africa, thus far (WHO 2011). Due to governmental and global actions, this region had the greatest increase in the absolute number of people receiving ART in 2010. However, $49 \%$ of the $5,064,000$ South Africans are still in need of medication (WHO 2011). Fortunately, there are fewer AIDS-related deaths since the introduction of ARTs in this region. Child mortality has dropped from 320,000 to 230,000 between 2005 and 2010. Currently, there are 108,682, children receiving ART medication (WHO 2011). Access to these drugs has significantly reduced AIDS- related deaths in KwaZulu-Natal, one of the sites of the current study. Thus, the most critical current challenge is helping an unprecedented number of children, with the support of their families, adhere to a complex medication regimen (WHO 2011).

Public Health Implications of Aging Cohorts of HIV+ Youth

The life circumstances of perinatally infected youth across global contexts are further complicated by the fact that even brief episodes of nonadherence to ART can permanently undermine their well-being and lead to the development of a multidrug-resistant strain of the virus. This grim reality becomes a serious public health issue as youth approach adolescence, a time of increased experimentation with sexual behavior and drug use. For HIV+ youth, engaging in any type of risk behavior increases opportunities for transmission of HIV (including ART-resistant strains of the virus) to others (Paterson et al. 2000). Again, there is serious need to support consistent ART adherence and address any emerging emotional and behavioral health needs of these youth as early as possible.

Emerging Mental Health Problems of Perinatally Infected Youth

A number of studies across the globe of perinatally HIV-infected youth suggest high rates of emotional and behavioral problems, including psychiatric disorders that are higher than noninfected inner-city youths and children with other chronic health conditions (Mellins and Malee 2013). In some studies, rates of psychiatric disorders including anxiety and behavioral disorders, specifically attention deficit hyperactivity disorders, have been reported, with rates as high as $60 \%$ of the samples (Mellins et al. 2009a; Gadow et al. 2010; Gadow et al. 2012). However, additional studies suggest that these mental health challenges may not be as pronounced as initially feared (Mellins and Malee 2013). Mental health challenges can negatively impact school performance, interpersonal interactions, and independent functioning over time (Wiener and Mellins 2010; Havens and Mellins 2008). Moreover, mental health problems are likely to interfere with youth ability to make decisions about negotiating situations of sexual possibility or experimentation with substances (Brown et al. 1997). Further, similar to adolescents with other chronic health conditions, the majority of perinatally infected adolescents evidence inconsistent adherence to their medications, which may result in poorly controlled HIV (MacDonell et al. 2013; Mellins et al. 2009b). The combination of poor adherence, increased sexual risk behavior, and substance use can substantively have a negative impact on the health and well-being of the infected youth. Moreover, HIV directly can impact the central nervous 
system (CNS), affecting neurocognitive function and mood regulation (Brouwers et al. 1991; Smith et al. 2006; Wiener and Mellins 2010). The impact of HIV on CNS functioning, as well as the surrounding stress of stigma and poverty, are likely to further impact the emotional well-being of perinatally HIVinfected youths (Mellins and Malee 2013: Brown et al. 2000; Aneshensel and Clea 1996). The lack of resources due to economic deprivation in poverty-impacted communities across country contexts can make these problems exponentially more severe.

Thus, as youth reach adolescence, the existing literature suggests that mental health and developmental challenges emerge, adherence plummets, and risk-taking increasesand all without any evidence-informed interventions to address these needs. This study examines one of the only evidence-informed interventions to promote mental health and health in pHIV+ youth with data pooled and analyzed from three separate studies involving preadolescent and earlyadolescent perinatally infected youth and their caregivers in three countries, CHAMP+ US, CHAMP+ Argentina, and CHAMP+ South Africa (SA).

Brief History of Collaborative HIV Prevention and Adolescent Mental Health Project

CHAMP+ is based on CHAMP, a program originally created to promote resilience in uninfected inner-city youth and their families in the mid-1990s. The intervention stemmed from work with early adolescents living in high seroprevalence communities in Chicago (CHAMP Southside). One of the basic tenets of CHAMP related to the commitment to partner with community members to provide interventions that were effective and nonexploitive. CHAMP attempted to strengthen familial relationships as a mechanism for addressing youth risk-taking behaviors. The intervention provided youth and their families with opportunities to improve their communication (particularly around sensitive topics they found hard to discuss related to puberty, sexuality, and sexual and drug risktaking). CHAMP multifamily meetings created a forum for safe communication about these topics within and across families. Further, family decision-making and parent monitoring skills were also targets as a means for creating a strong adult health protective shield for youth living in high seroprevalence neighborhoods (McKay and Paikoff 2007; Bell et al. 2007; Bhana et al. 2010).

Numerous studies reveal high rates of involvement and retention in the CHAMP Family Program. There are significant associations between CHAMP and improvements in family decision-making, communication, and time spent by youth spend in situations of sexual possibility (McKay and Paikoff 2007; McBride et al., in press; McKay et al. 2007; Bell et al. 2007).
In 2001, CHAMP was adapted into CHAMP+ US for two hospitals in New York City with large pediatric HIV clinics. Its adaptation was based on needs specific to perinatally infected youth and their adult caregivers. In designing this CHAMP+ intervention, youth, parents, and medical and psychosocial provider consultants were intensely involved in the creation of the program. As a result, the content of the CHAMP Family Program materials was modified, although the overall structure, number of sessions, and select activities remained unchanged (see McKay et al. 2007 for a description).

In 2007, providers from South Africa reached out to CHAMP+ investigators with requests for evidence-informed interventions for their growing adolescent population. With funding from the NIH, further adaptations were made to program materials and method of delivery based on a small pilot trial (Bhana et al. 2014). In South Africa, CHAMP+ SA was informed by the substantial HIV prevention work of several previous investigators in South Africa (see Bell et al. 2007 for a description), as well as the significant history of Apartheid and poverty for Black South Africans; the substantive stigma of HIV/AIDS in this context; and intense collaboration with HIV+ youth, their adult caregivers, and medical staff responsible for creating the emerging pediatric care systems in KwaZulu-Natal, one of the South African provinces with the highest HIV seroprevalence in the world (Abdool Karim and Abdool Karim 2002; Parker and Aggleton 2003; Simbayi et al. 2007). The resulting intervention protocol retained the overall structure and much of the content of CHAMP+ US, but a cartoon-based participatory approach was used to address stigma, low literacy, and the taboo nature of parents and children discussing sexual topics (see Bhana et al. 2004; Petersen et al. 2006 for a description). In 2010, this same development process of CHAMP+ materials began in Buenos Aires, Argentina. Across sites, even though there were significant changes made to the intervention to enhance cultural and contextual relevance, the goals, content, and targets of CHAMP+ remained quite similar (see McKay et al., in press; Bhana et al. 2014 for details regarding each intervention).

\section{Methods}

\section{Overview}

Data for this study come from three small pilot randomized controlled trials (RCTs). The CHAMP+ US data was collected in 2006. The sample involves 24 families, all with HIV+ youth receiving medical care at the same urban hospital in New York City. The CHAMP+ Argentina participants included 22 youth and their families, also receiving care at an urban pediatric specialty hospital in Buenos Aires. Interviews 
occurred in 2010. All participants were Spanish speaking. The $\mathrm{CHAMP}+$ South Africa sample was involved most recently (2009-2011). Caregivers were approached in HIV clinic waiting rooms of two differing hospitals in KwaZuluNatal, South Africa. Among the 74 families recruited, 65 families were enrolled.

A secondary analysis of data collected over time across the three global sites was performed. Univariate analyses were applied first to data captured via standardized scales across country contexts to identify site-specific and universal mental health need. Next, multivariate analysis was used to examine the impact of the site-specific versions of a family-strengthening intervention (CHAMP+ US, CHAMP+ Argentina, CHAMP+ SA) on domains identified by adult caregivers as areas of mental health concern relative to a randomized standard of care comparison on key mental health outcomes.

Sample

Overall, participants included 111 families, consisting of children and their caregivers. Gender of the children was evenly split, with 58 males and 48 females. On average, youth participants were 11.8 years $(\mathrm{SD}=1.25)$ across sites. Argentine children were the oldest, on average 12.8 years $(\mathrm{SD}=1.06)$, followed by the USA and South Africa [12.1 years $(\mathrm{SD}=1.24)$ and 11.6 years $(\mathrm{SD}=1.20)$, respectively].

The majority of adult caregivers were female (95 females vs. 12 males), single parents (never married), and had not completed high school. On average, caregivers were 44.9 years of age $(\mathrm{SD}=13.08)$. Caregiver characteristics differed significantly across sites. See Tables 1 and 2 .

Inclusion criteria for the study were as follows: (1) youth, ages 9 to 14 years, who were perinatally exposed to HIV and knew their diagnosis (given that HIV is discussed in the intervention); (2) participants were either English, Spanish, or Zulu speaking, depending on country context; and (3) the caregiver had to have the capacity to provide consent for the child's participation. Caregivers included biological parents, guardians, relatives, and adoptive parents. All caregivers provided written consent and youth assent, and IRB approvals were obtained in all countries.

For all three studies, interview procedures were similar. Youth and adult caregivers were interviewed at two assessment points, baseline before randomization and posttest (approximately 3 months from baseline).

\section{Measures}

Child Mental Health Child mental health was measured by the Strengths and Difficulties Questionnaire (SDQ). The 25item measure is a well-validated and globally used measure of emotional and behavioral functioning (Goodman 1997;
Table 1 Demographic characteristics of participants pooled across sites

\begin{tabular}{|c|c|c|}
\hline Variables & Total $N$ & Mean (SD) or percentage \\
\hline \multicolumn{3}{|l|}{ Site (families) } \\
\hline Argentina & 22 & \\
\hline South Africa & 65 & \\
\hline USA & 24 & \\
\hline \multicolumn{3}{|l|}{ Caregiver characteristics } \\
\hline Gender & 106 & \\
\hline Male & 12 & $10.7 \%$ \\
\hline Female & 94 & $85.7 \%$ \\
\hline Age & 106 & \\
\hline Male & 12 & $43.3(10.5)$ \\
\hline Female & 94 & $45.1(13.5)$ \\
\hline Relationship status & 103 & \\
\hline Married & 35 & $33 \%$ \\
\hline Separated (from spouse) & 6 & $5.4 \%$ \\
\hline Single (never married) & 39 & $34.8 \%$ \\
\hline Single (divorced) & 7 & $6.3 \%$ \\
\hline Single (widowed) & 14 & $12.5 \%$ \\
\hline Employment status & 84 & \\
\hline Yes & 37 & $34.8 \%$ \\
\hline No & 47 & $42 \%$ \\
\hline Education & 104 & \\
\hline Eighth grade or less & 31 & $28.2 \%$ \\
\hline Some high school & 35 & $31.8 \%$ \\
\hline Completed high school & 20 & $18.2 \%$ \\
\hline Some college & 12 & $10.9 \%$ \\
\hline Completed college & 2 & $1.8 \%$ \\
\hline Post college & 4 & $3.6 \%$ \\
\hline Housing type & 104 & \\
\hline Yes, live in own place & 72 & $66.1 \%$ \\
\hline No & 31 & $27.7 \%$ \\
\hline Other & 1 & $0.9 \%$ \\
\hline Number of people in home & 105 & $5.5(2.9)$ \\
\hline \multicolumn{3}{|l|}{ Child characteristics } \\
\hline Gender & 106 & \\
\hline Male & 58 & $52.7 \%$ \\
\hline Female & 48 & $43.6 \%$ \\
\hline Age & 105 & \\
\hline Male & 58 & $12.1(1.3)$ \\
\hline Female & 47 & $11.70(1.18)$ \\
\hline
\end{tabular}

Goodman et al. 1998; Goodman 1999). It has five subscales - emotional problems, conduct problems, hyperactivity, peer relationship problems, and prosocial behavior. Parents rate their children's behaviors on items such as "My child often loses temper," and "My child has at least one good friend." Using a three-point scale from 0 (not true), 1 (somewhat true), to 2 (certainly true), a high score indicates higher endorsement of the behavior domain (excluding the inverse 
Table 2 Demographic characteristics by site

\begin{tabular}{|c|c|c|c|c|c|c|}
\hline & \multicolumn{2}{|c|}{ Argentina } & \multicolumn{2}{|c|}{ South Africa } & \multicolumn{2}{|l|}{ USA } \\
\hline & Total $N$ & $\begin{array}{l}\text { Mean } N(\mathrm{SD}) \\
\text { or percentage }\end{array}$ & Total $N$ & $\begin{array}{l}\text { Mean } N(\mathrm{SD}) \\
\text { or percentage }\end{array}$ & Total $N$ & $\begin{array}{l}\text { Mean } N(\mathrm{SD}) \\
\text { or percentage }\end{array}$ \\
\hline \multicolumn{7}{|l|}{ Caregiver demographics } \\
\hline \multicolumn{7}{|l|}{ Gender } \\
\hline Male & 3 & $15 \%$ & 6 & $9.10 \%$ & 3 & $12.50 \%$ \\
\hline Female & 17 & $85 \%$ & 59 & $89.40 \%$ & 18 & $75 \%$ \\
\hline Age* & 20 & $41.9(10.4)$ & 65 & $43.0(13.2)$ & 21 & $53.5(12.4)$ \\
\hline Male & 3 & $41.3(5.8)$ & 6 & $38.8(6.8)$ & 3 & $54.0(14.8)$ \\
\hline Female & 17 & $42.0(11.1)$ & 59 & $43.4(13.2)$ & 18 & $53.4(12.5)$ \\
\hline \multicolumn{7}{|l|}{ Education } \\
\hline Eighth grade or less & 9 & $45 \%$ & 22 & $33.30 \%$ & 0 & \\
\hline Some high school & 10 & $50 \%$ & 19 & $28.80 \%$ & 6 & $25 \%$ \\
\hline Completed high school & 1 & $5 \%$ & 13 & $19.70 \%$ & 6 & $25 \%$ \\
\hline Some college & 0 & 0 & 4 & $6.10 \%$ & 8 & $33.30 \%$ \\
\hline Completed college & 0 & 0 & 1 & $1.50 \%$ & 1 & $4.20 \%$ \\
\hline Post college & 0 & 0 & 4 & $6.10 \%$ & 0 & \\
\hline \multicolumn{7}{|l|}{ Relationship status } \\
\hline Married & 8 & $40 \%$ & 21 & $31.80 \%$ & 6 & $25 \%$ \\
\hline Separated (from spouse) & 1 & $5 \%$ & 3 & $4.50 \%$ & 2 & $8.30 \%$ \\
\hline Single (never married) & 4 & $20 \%$ & 29 & $43.90 \%$ & 6 & $25 \%$ \\
\hline Single (divorced) & 1 & $5 \%$ & 2 & $3 \%$ & 4 & $16.70 \%$ \\
\hline Single (widowed) & 5 & $25 \%$ & 7 & $10.60 \%$ & 2 & $8.30 \%$ \\
\hline \multicolumn{7}{|l|}{ Child demographics } \\
\hline \multicolumn{7}{|l|}{ Gender } \\
\hline Male & 12 & $60 \%$ & 33 & $51 \%$ & 13 & $60 \%(1.13)$ \\
\hline Female & 8 & $40 \%$ & 32 & $49 \%$ & 8 & $40 \%(1.30)$ \\
\hline Age* & 20 & $12.8(1.1)$ & 65 & $11.6(1.2)$ & 21 & $12.1(1.2)$ \\
\hline Male & 12 & $13(1.1)$ & 33 & $11.6(1.2)$ & 13 & $12.5(1.1)$ \\
\hline Female & 8 & $12.5(0.9)$ & 31 & $11.5(1.2)$ & 8 & $11.6(1.3)$ \\
\hline
\end{tabular}

Caregivers in the USA are significantly older than those in Argentina and South Africa $(p<.05)$

Youth in Argentina are significantly older than those in South Africa $(p<.05)$

score prosocial subscale). A total difficulties score is calculated by summing up the raw scores of the first four subscales. In previous research, the SDQ correlated highly with the Child Behavior Checklist (Goodman and Scott 1999). Internal consistency is satisfactory (0.73). Average test-retest reliability is 0.62 (Goodman 2001). The SDQ has been adapted in multiple languages across the globe including Zulu (the language for $\mathrm{CHAMP}+\mathrm{SA}$ ) and Spanish (used in CHAMP+ Argentina).

\section{CHAMP+ Demographic Questionnaire}

Demographic characteristics were captured from caregiver and child batteries that were adapted to each country. Demographic items that matched across sites were selected for comparison. Both caregivers and children responded to questions regarding age, gender, and education. Caregivers provided further information regarding their relationship status and housing information. Items were open ended, as well as multiple choice.

\section{Data Analysis}

First, univariate analysis was used to compare baseline mean SDQ subscale scores across the three CHAMP+ global sites, as well as examine demographic differences across country contexts. Next, logistic regression analyses were used to compare the proportion of youth at posttest who moved from having scores in the clinically symptomatic range on standardized measures to having scores within normative ranges 
by condition (CHAMP+ vs. standard of care). Post hoc analyses were applied to identify the site differences.

\section{Results}

Results are summarized in Tables 3, 4, and 5.

At baseline, the vast majority of caregivers reported that their children were not experiencing serious behavioral difficulties. Overall, $95 \%$ of adult caregivers reported that their children's total difficulties fell within the normal range on the SDQ. More specifically, $97 \%$ of caregivers at baseline described their child's peer relations as being within normal limits; 94 and $88 \%$ of all adult caregivers described their children as being without hyperactivity and conduct-related difficulties, respectively. Two areas did emerge as being more problematic from adult caregivers' perspectives. Slightly less than half (49\%) described their children as presenting serious or emerging symptoms of emotional distress. Further, $80 \%$ of adult caregivers described their children as needing serious improvement in prosocial behavior.

Some significant site differences did emerge. For example, in South Africa, adult caregivers reported that a significant proportion of children did not have serious mental health challenges. More specifically, parents reported that children were not experiencing difficulties in the following areas: conduct (90\%), hyperactivity (89\%), peer problems (89\%), and total difficulties (82 \%). However, only $46 \%$ of caregivers described their children's emotional health as being in the normal range. Further, the vast majority of adult caregivers expressed concerns regarding their child's prosocial behavior (91 \%).

Similarly in Argentina, $40 \%$ of adult caregivers expressed serious concern regarding their child's emotional well-being. However, in contrast to South Africa, only $4 \%$ expressed any serious concern regarding their child's prosocial behavior. Approximately $25 \%$ of adults in Argentina described their child's total difficulties as being in the clinically serious range.
Table 4 Baseline means comparisons

\begin{tabular}{|c|c|c|c|c|c|c|}
\hline & \multicolumn{2}{|c|}{ Argentina } & \multicolumn{2}{|c|}{ South Africa } & \multicolumn{2}{|l|}{ USA } \\
\hline & Mean & SD & Mean & SD & Mean & $\mathrm{SD}$ \\
\hline Caregiver age & $41.9^{\mathrm{a}}$ & 10.4 & $43.0^{\mathrm{b}}$ & 13.2 & $53.5^{\mathrm{ab}}$ & 12.4 \\
\hline Child age & $12.8^{\mathrm{a}}$ & 1.1 & $11.6^{\mathrm{a}}$ & 1.2 & 12.1 & 1.2 \\
\hline Emotional symptoms & 3.4 & 2.0 & 4.0 & 2.8 & 3.1 & 2.4 \\
\hline Conduct problems & $2.9^{\mathrm{ab}}$ & 1.6 & $0.8^{\mathrm{a}}$ & 0.9 & $0.5^{\mathrm{b}}$ & 0.8 \\
\hline Hyperactivity subscale & $3.75^{\mathrm{ab}}$ & 2.1 & $0.3^{\mathrm{a}}$ & 0.7 & $0.4^{\mathrm{b}}$ & 0.8 \\
\hline Peer problems subscale & 1.0 & 1.4 & 0.6 & 0.8 & 0.5 & 0.8 \\
\hline Prosocial subscale & $7.2^{\mathrm{ab}}$ & 0.9 & $0.2^{\mathrm{a}}$ & 0.6 & $0.3^{\mathrm{b}}$ & 0.7 \\
\hline Total difficulties & $11.1^{\mathrm{ab}}$ & 3.7 & $0.6^{\mathrm{a}}$ & 0.9 & $0.4^{\mathrm{b}}$ & 0.6 \\
\hline
\end{tabular}

Groups with a common alphabetic superscript within a row are statistically significant from each other using a Bonferroni post hoc test with an alpha level of 0.05

This assessment of child need was distinct from the other two sites.

In comparison, in the USA, fewer adult caregivers reported serious concern regarding the presence of emotional distress in their children (29\%) and $0 \%$ of the sample was viewed by their adult caregivers as having behavioral problems in the abnormal range (including total scores, conduct problems, hyperactivity, and peer difficulties). Only in the area of prosocial behavior did adult caregivers express concern, with $100 \%$ of caregivers noting this area as a serious challenge for their children. See Table 3 for a summary of these results.

Further, in examining baseline mean scores, some additional site differences did emerge. Overall, site was significantly related to child difficulty scores at the $p<0.001$ level for conduct $[F(2,97)=36.33, p<0.001]$, hyperactivity $[F(2,96)=$ $76.19, p<0.001]$, prosocial $[F(2,96)=381.04 ; p<0.001]$, and total difficulties $[F(2,90)=261.41, p<0.001]$. As noted in Table 4, youth from the Argentina site were rated significantly worse by their adult caregivers on behavioral difficulties, total difficulties, and prosocial behaviors relative to the USA and South Africa. Yet, despite these significant differences, only

Table 3 Proportion of adult caregiver ratings of youth by scores falling in normal vs. borderline/serious concern range

\begin{tabular}{lllll}
\hline & $\begin{array}{l}\text { Argentina } \\
\text { Percentage of scores } \\
\text { in normal range }\end{array}$ & $\begin{array}{l}\text { South Africa } \\
\text { Percentage of scores } \\
\text { in normal range }\end{array}$ & $\begin{array}{l}\text { USA } \\
\text { Percentage of scores } \\
\text { in normal range }\end{array}$ & $\begin{array}{l}\text { Total across sites } \\
\text { Percentage of scores } \\
\text { in normal range }\end{array}$ \\
\hline Emotional symptoms & 60 & 46 & 74 & 51 \\
Conduct problems & 40 & 90 & 100 & 88 \\
Hyperactivity & 70 & 89 & 100 & 94 \\
Peer problems & 85 & 89 & 100 & 97 \\
Prosocial behavior & 95 & 9 & 0 & 19 \\
Total difficulties & 75 & 82 & 100 & 95 \\
\hline
\end{tabular}


Table 5 Subscale means for emotional symptoms and prosocial behaviors by condition across sites

\begin{tabular}{|c|c|c|c|c|c|c|}
\hline & \multicolumn{2}{|c|}{ Argentina } & \multicolumn{2}{|c|}{ South Africa } & \multicolumn{2}{|l|}{ USA } \\
\hline & Mean & SD & Mean & SD & Mean & SD \\
\hline \multicolumn{7}{|c|}{$\begin{array}{l}\text { Emotional symptoms } \\
\text { subscale time } 1\end{array}$} \\
\hline Experimental & 3.10 & 2.03 & 3.94 & 2.64 & 3.5 & 2.6 \\
\hline Control & 3.70 & 1.95 & 4.14 & 3.08 & 2.0 & 1.41 \\
\hline \multicolumn{7}{|c|}{$\begin{array}{l}\text { Emotional symptoms } \\
\text { subscale time } 2\end{array}$} \\
\hline Experimental & 2.50 & 3.54 & 3.22 & 2.13 & 2.3 & 2.2 \\
\hline Control & 5.00 & 2.73 & 3.78 & 2.38 & 1.8 & 1.3 \\
\hline \multicolumn{7}{|c|}{ Prosocial subscale time 1} \\
\hline Experimental & 7.00 & 0.67 & 0.26 & 0.68 & 0.29 & 0.61 \\
\hline Control & 7.30 & 1.06 & 0.17 & 0.54 & 0.40 & 0.89 \\
\hline \multicolumn{7}{|c|}{ Prosocial subscale time 2} \\
\hline Experimental & 9.50 & 0.71 & 8.23 & 2.05 & 7.19 & 2.32 \\
\hline Control & 9.13 & 1.64 & 8.21 & 1.64 & 8.60 & 1.52 \\
\hline
\end{tabular}

prosocial behavioral scores fell outside the normal range. There were no observed differences between the mean scores of the USA and South Africa for child behavior symptoms. Further, in relation to demographic difference across sites, caregivers in Argentina were significantly older than those in the USA and South Africa.

Regarding change over time (Table 5), we focused on the two areas of expressed need by adult caregivers: child emotional distress and prosocial behavioral skills. Pooling children and families across sites, adult caregivers whose children were randomly assigned to the site-specific CHAMP+ intervention were significant more likely to report that their child's emotional symptoms fell within the normal range at posttest, controlling for pretest scores $(B=-1.11$; $\mathrm{SE}=0.55$; $\operatorname{Exp}(B)=0.325 ; p<0.05)$ relative to those children receiving standard of care in their respective HIV clinics. In relation to prosocial behavior, there was a trend towards improvement of children assigned to the experimental intervention; however, findings were not significant between conditions $(B=1.6$; $\mathrm{SE}=1.1 ; \operatorname{Exp}(B)=4.8 ; p<0.10)$. Post hoc analyses revealed no significant differences by site in relation to improvement in emotional functioning. In relation to prosocial behaviors, trends for more improvements for South African and US youth based on parent reports trended towards significance.

\section{Discussion}

Perinatally infected youth with ongoing access to ART are continuing to enter adolescence. The "real world" challenges of stigma, poverty, access to health care, peer relationships, transmission risks, and family dynamics place confounding pressures on these youth and their caregivers. CHAMP+ attempts to address some of these factors. This is one of the first papers to compare HIV-infected children's needs across global sites. It also compares international mental health outcomes of an evidence-informed, family-focused intervention. Findings suggest that perinatally infected youth are evidencing considerable resilience in relation to their mental health, particularly related to more externalizing (e.g., conduct, hyperactivity) behavioral difficulties. However, adult caregivers do express significantly more concern regarding their children's emotional and prosocial functioning. At baseline, caregivers in Argentina reported more impairment in youth conduct, hyperactivity, and total difficulties in comparison to those in South Africa and the USA. Parents expressed more concern for their child's emotional health and in some country contexts, their prosocial skills. Multivariate analyses revealed improvement in relation to emotional functioning and a trend towards enhancement in prosocial behaviors for those youth participating in the CHAMP+ family programs relative to standard of care. No global site differences were noted regarding child emotional functioning and some impairment (South Africa and USA) emerging in relation to prosocial functioning. Despite a relatively small sample of youth and families involved in the experimental study of CHAMP across the three sites, there is indication that this could be a helpful support aimed at improving emotional functioning of HIV+ youth as they age into adolescence.

This study does have limitations. Culture plays an important role on how these caregivers perceive their children (Mieh et al. 2013; Stone et al. 2010). This paper does not address the impact of culture on parent reports. Although the SDQ is available in Spanish, it has not been empirically tested among Argentine participants per se. Caregiver ratings in Argentina surpassed those in the USA and SA. Child 
age may be an influence. Additional research is needed to explore whether cultural beliefs about appropriate child behaviors or language differences related to translation could be a factor here.

CHAMP+ has evolved over time, as have its data collection methods. CHAMP+ is implemented by local providers. In Argentina and the USA, the program was delivered by professionals with mental health training, namely, health educators, psychologists, and psychiatrists. In South Africa, although a psychologist was the group leader, coleaders included lay counselors with very little, if any, training delivered the program. Although this familiarity with providers may enhance engagement, it may also make the studies vulnerable to participant biases. The low mean scores at baseline for the USA and SA may have resulted from social desirability bias or acquiescent reporting.

Although, we were able recruit participants who met criteria for our study, this convenience sample may not reflect the larger population of HIV-impacted families within broader country contexts of Argentina, South Africa, and the USA. Despite these limitations, there are positive signals that a culturally and contextually tailored intervention may contribute positively to youth mental health over the short term. Only children whose HIV diagnosis had been disclosed to them were included in the study. We did not access children who were not told their diagnosis, who may be more at risk.

A family-based intervention such as CHAMP+ may have positive sustainable outcomes for HIV-impacted families across global contexts. Continued partnerships with community stakeholders and collaborative groups (local leaders, health workers, teachers, and caregivers) such as those in South Africa, Argentina, and the USA helped CHAMP+ become a sustainable model. Knowledge gained from work across these sites provides evidence of the adaptability of $\mathrm{CHAMP}+$ to specific contextual needs for ongoing and future studies. Globally, as seropositive youth continue to navigate through adolescence, CHAMP+ remains a collaborative, adaptive, and empirically informed intervention to support HIV+ youth and prevent risk-taking behaviors. The lack of resources due to economic deprivation in poverty-impacted communities can make complex problems faced by perinatally infected adolescents exponentially more severe (i.e., emotional functioning, prosocial and conduct difficulties). However, HIV-impacted families also demonstrate resilience. Evidence-informed interventions can be tailored to bolster participant strengths while addressing areas of high need.

The impact of HIV on perinatally infected youth and their caregivers continues to be a global concern. Evidenceinformed psychosocial interventions are needed to support youth emotional behavioral outcomes internationally. Ongoing collaborations with community members in adapting
CHAMP + to future country contexts can contribute to global social welfare practice and potentially inform international policies on care systems for HIV-impacted families of seropositive youth.

Acknowledgments We gratefully acknowledge the grant support from the National Institutes of Health [R03 DA024572-PI: McKay (CHAMP+ Argentina), R21 NR010474-PI: Mellins (CHAMP+ SA), R34 MHO72382-PI: McKay (CHAMP+ US), and R01 HD074052-PI: McKay (VUKA Family Program: Supporting Perinatally HIV+ Youth in South Africa)]. In addition, we wish to thank participating families and research staff, including our collaborators at the Human Sciences Research Council (Bhana), University of KwaZulu-Natal (Petersen), Harlem Hospital (Abrams), and Hospitale de Garrahan (Bologna, Borgata).

\section{References}

Abdool Karim, Q., \& Abdool Karim, S. S. (2002). The evolving HIV epidemic in South Africa. Int Journal of Epidemiology, 31(1), 3740. doi:10.1093/ije/31.1.37.

Abrams, E. J., \& Nicholas, S. W. (1990). Pediatric HIV infection. Pediatric Annals, 19(8), 482-483. 485-487.

Abrams, E. J., Weedon, J., Bertolli, J., Bornschlegel, K., Crevia, J., Mendez, H., et al. (2011). Aging cohort of perinatally human immunodeficiency virus-infected children in New York City. Pediatric Infectious Disease Journal, 20(5), 511-517.

Aneshensel, C. S., \& Clea, C. A. (1996). The neighborhood context of adolescent mental health. Journal of Health and Social Behavior, 37(4), 293-310.

Bell, C., Bhana, A., McKay, M., \& Petersen, I. (2007). A commentary on the Triadic Theory of Influence as a guide for adapting HIV prevention programs for new contexts and populations: the CHAMP-South Africa story. Social Work in Mental Health, 5(3/4), 243-267.

Bhana, A., Petersen, I., Mason, A., Mahintsho, Z., Bell, C., \& McKay, M. (2004). Children and youth at risk: adaptation and pilot study of the CHAMP (Amaqhawe) programme in South Africa. African Journal of AIDS Research (AJAR), 3(1), 33-41.

Bhana, A., McKay, M., Mellins, C. A., Petersen, I., \& Bell, C. (2010). Family-based HIV prevention and intervention services for youth living in poverty-affected contexts: the CHAMP model of collaborative, evidence-informed programme development. Journal of the International AIDS Society, 13(Suppl 2), S8.

Bhana, A., Mellins, C. A., Petersen, I., Alicea, S., Myeza, N., Holst, H., et al., (2014). The VUKA family program: piloting a family-based psychosocial intervention to promote health and mental health among HIV infected early adolescents in South Africa. AIDS Care, 1(26), 1-11.

Blanco, M., Re, M. I., Pagani, L., \& Barone, S. (1998). Latin American and the Caribbean Council of AIDS Service Organizations, UNAIDS (1998). Argentina: Human Rights and Access to Treatment for HIV.

Brouwers, P., Belman, A. L., \& Epstein, L. G. (1991). Central nervous system involvement: manifestations and evaluation. In P. Pizzo \& C. Wilfert (Eds.), Pediatric AIDS: the challenge of HIV infection in infants (pp. 318-335). Baltimore, MD: Children and Adolescents. Williams and Wilkins.

Brown, L. K., Danovsky, M. B., Lourie, K. J., DiClemente, R. J., \& Ponton, L. E. (1997). Adolescents with psychiatric disorders and the risk of HIV. Journal of the American Academy of Child and Adolescent Psychiatry, 36(11), 1609-1617. 
Brown, L. K., Lourie, K. J., \& Pao, M. (2000). Children and adolescents living with HIV and AIDS: a review. Journal of Child Psychology and Psychiatry, 41, 81-96.

Center for Disease Control and Prevention. (1994). Recommendations of the U.S. Public Health Service Task Force on the use of zidovudine to reduce perinatal transmission of human immunodeficiency virus. MMWR 1994 / 43(No. RR11);1-20 . Retrieved from http://www. cdc.gov/mmwr/preview/mmwrhtml/00032271.htm

Center for Disease Control and Prevention. (2012) HIV among pregnant women, infants, and children in the United States (2010) Retrieved from http://www.cdc.gov/hiv/pdf/risk_WIC.pdf

Central Intelligence Agency (2011). "CIA World Factbook 2011—people living with the HIV virus". Retrieved from: https://www.cia.gov/ library/publications/the-world-factbook/rankorder/2156rank.html.

Chin, J. (1990). Current and future dimensions of the HIV/AIDS pandemic in women and children. The Lancet, 336, 221-224.

Cluver, L., \& Orkin, M. (2009). Stigma, bullying, poverty and AIDSorphanhood: interactions mediating psychological problems for children in South Africa. Social Science and Medicine, 69(8), 1186-1193.

Cluver, L., Gardner, F., \& Operario, D. (2007). Psychological distress amongst AIDS-orphaned children in urban South Africa. Journal of Child Psychology and Psychiatry, 48(8), 1469-7610.

Cunningham, W. E., Hayes, R. D., Williams, K. W., Beck, K. C., Dixon, W. J., \& Shapiro, M. F. (1995). Access to medical care and healthrelated quality of life for low-income, symptomatic, HIV-infected individuals. Medical Care, 33(7), 739-754.

Deeks, G., Lewin, S. R., \& Havlir, D. V. (2013). The end of AIDS: HIV infection as a chronic disease. The Lancet, 382(9903), 1525-1533. doi:10.1016/S0140-6736(13)61809-7.

Domek, G. (2006). Social consequences of antiretroviral therapy: preparing for the unexpected futures of HIV-positive children. The Lancet, 367(9519), 1367-1369.

Elkington, K. S., Robbins, R. N., Bauermeister, J. A., Abrams, E. J., McKay, M., Mellins, C. A. (2011). Mental health in youth infected with and affected by HIV: the role of caregiver HIV. Journal of Pediatric Psychology, 36(3), 360-373.

Gadow, K. D., Chernoff, M., Williams, P. L., Brouwers, P., Morse, E., Heston, J., et al. (2010). Co-occurring psychiatric symptoms in children perinatally infected with HIV and peer comparison sample. Journal of Developmental and Behavioral Pediatrics, 31, 116-128.

Gadow, K. D., Angelidou, K., Chernoff, M., Williams, P. L., Heston, J., Hodge, J., et al. (2012). Longitudinal study of emerging mental health concerns in youth perinatally-infected with HIV and peer comparisons. Journal of Developmental and Behavioral Pediatrics, 33, 456-468.

Garcia, P. M., Kalish, L. A., Pitt, J., Minkoff, H., Quinn, T. C., Burchett, S. K., et al. (1999). Maternal levels of plasma human immunodeficiency virus type 1 RNA and the risk of perinatal transmission. New England Journal of Medicine, 341, 394-402.

Goodman, R. (1997). The Strengths and Difficulties Questionnaire: a research note. Journal of Child Psychology and Psychiatry, 38, 581586.

Goodman, R. (1999). The extended version of the Strengths and Difficulties Questionnaire as a guide to child psychiatric caseness and consequent burden. Journal of Child Psychology and Psychiatry, 40, 791-801.

Goodman, R. (2001). Psychometric properties of the Strengths and Difficulties Questionnaire (SDQ). Journal of the American Academy of Child and Adolescent Psychiatry, 40, 1337-1345.

Goodman, R., \& Scott, S. (1999). Comparing the Strengths and Difficulties Questionnaire and the Child Behavior Checklist: is small beautiful? Journal of Abnormal Child Psychology, 27, 17-24.

Goodman, R., Meltzer, H., \& Bailey, V. (1998). The Strengths and Difficulties Questionnaire: a pilot study on the validity of the self- report version. European Child and Adolescent Psychiatry, 7, 125130.

Gopalan, G., Baugh, C., \& McKay, M.M. (2012). HIV prevention with adolescents. Oxford Bibliographies Online. Available online: http:// www.ox fordbibliographies.com/view/document/obo9780195389678/obo-9780195389678-0061.xml

Havens, J. F., \& Mellins, C. A. (2008). Psychiatric aspects of HIV/AIDS in childhood and adolescence. In M. Rutter \& E. Taylor (Eds.), Child and adolescent psychiatry (5th ed., pp. 828-841). Oxford: Blackwell.

Kang, E., Mellins, C. A., Dolezal, C., Elkington, K. S., \& Abrams, E. J. (2011). Disadvantaged neighborhood influences on depression and anxiety in youth with perinatally acquired human immunodeficiency virus: how life stressors matter. Journal of Community Psychology, 39, 956-971. doi:10.1002/jcop.20483.

MacDonell, K., Naar-King, S., Huszti, H., \& Belzer, M. (2013). Barriers to medication adherence in behaviorally and perinatally infected youth living with HIV. AIDS Behavior, 17(1), 86-93. doi:10.1007/ s10461-012-0364-1.7610.00550.

McKay, M., \& Paikoff, R. (Eds.). (2007). Community collaborative partnerships: the foundation for HIV prevention research efforts in the United States and internationally. West Hazleton, PA: Haworth Press.

McKay, M., Block, M., Claude Mellins, C. A., Traube, D. E., BrackisCott, E., Minott, D., et al. (2007). Adapting a family-based HIV prevention program for HIV-infected preadolescents and their families. Social Work in Mental Health, 5(3-4), 355-378.

Mellins, C. A., \& Malee, K. M. (2013). Understanding the mental health of youth living with perinatal HIV infection: lessons learned and current challenges. Journal of the International AIDS Society, 16, 18593.

Mellins, C. A., Brackis-Cott, E., Dolezal, C., \& Abrams, E. J. (2006). Psychiatric disorders in youth with perinatally acquired human immunodeficiency virus infection. The Pediatric Infectious Disease Journal, 25, 432-437.

Mellins, C. A., Brackis Cott, E., Leu, C., Elkington, K., Dolezal, C., Wiznia, A., et al. (2009a). Rates and types of psychiatric disorders in perinatally human immunodeficiency virus-infected youth and seroreverters. Journal of Child Psychology and Psychiatry, 50, 1131-1138. PMC2775808.

Mellins, C. A., Havens, J. F., McDonnell, C., Lichtenstein, C., Udall, K., Chesney, M., et al. (2009b). Adherence to antiretroviral medications and medical care in HIV-infected adults diagnosed with mental and substance abuse disorders. AIDS Care, 21, 68-177. PMC exempt: Accepted before $4 / 08$.

Mieh, T., Iwelunmor, J., \& Airhihenbuwa, C. O. (2013). Home-based caregiving for people living with HIV/AIDS in South Africa. Journal of Health Care for the Poor and Underserved, 24(2), 697-705. doi:10.1353/hpu.2013.0091.

New York City Department of Health and Mental Hygiene. (2012). Pediatric HIV/AIDS Surveillance Update New York City, Data Reported through 12/31/2011. Annual Report. HIV Epidemiology and Field Services Program. Retrieved from http://www.nyc.gov/ $\mathrm{html} / \mathrm{doh} / \mathrm{html} /$ data/epi-reports.shtml\#ped

Newell, M. L., Coovadia, H., Cortina Borja, M., Rollins, N., Gaillard, P., \& Dabis, F. (2004). Mortality of infected and uninfected infants born to HIV-infected mothers in Africa: a pooled analysis. The Lancet, 364(9441), 1236-1243. Publisher Full Text.

Nicoll, A., Timaeus, I., Kigadye, R. M., Walraven, G., \& Killweo, J. (1994). The impact of HIV-1 infection on mortality in children under 5 years of age in sub-Saharan Africa: a demographic and epidemiologic analysis. AIDS, 8(7), 995-1005.

Pan American Health Organization (2013). 2012 progress report: elimination of mother-to-child transmission of HIV and congenital syphilis in the Americas. Washington, D.C.: Pan American Health Organization. 
Parker, R., \& Aggleton, P. (2003). HIV and AIDS-related stigma and discrimination: a conceptual framework and implications for action. Social Science \& Medicine, 57, 13-24.

Paterson, D. L., Swindells, S., Mohr, J., Brester, M., Vergis, E. N., et al. (2000). Adherence to protease inhibitor therapy and outcomes in patients with HIV infection. Annals of Internal Medicine, 133, 2130.

Pearlstein, S. L., Mellins, C. A., Dolezal, C., Elkington, K. S., Santamaria, E. K., Leu, C. S., et al. (2013). Youth in transition: life skills among perinatally HIV-infected and HIV-exposed adolescents. Journal of Pediatric Psychology. doi:10.1093/jpepsy/ jst077.

Petersen, I., Mason, A., Bhana, A., Bell, C., \& McKay, M. (2006). Mediating social representations using targeted micro media in the form of a cartoon narrative in the context of HIV/AIDS: The AmaQhawe Family Project (CHAMP) in South Africa. Journal of Health Psychology, 11, 197-206.

Simbayi, L. C., Kalichman, S., Strebel, A., Cloete, A., Hende, N., \& Mqeketo, A. (2007). Internalized stigma, discrimination, and depression among men and women living with HIV/AIDS in Cape Town. South Africa. Social Science and Medicine, 64, 1823-1831.

Smith, R., Malee, K., Leighty, R., Brouwers, P., Mellins, C., Hittelman, J., Women and Infants Transmission Study Group, et al. (2006). Effects of perinatal HIV infection and associated risk factors on cognitive development among young children. Pediatrics, 117, 851-862.

South Africa Department of Health Operational Plan for Comprehensive Treatment and Care for HIV and AIDS. 2003.

South Africa Medical Research Council (MRC) (2011). SA PMTCT Evaluation shows that virtual elimination of paediatric HIV is possible with intensified effort. Accessed at http://www.mrc.ac.za/ pressreleases/2011/10press2011.htm.

Stone, L. L., Otten, R., Engels, R. C. M. E., Vermulst, A. A., \& Janssens, J. M. A. M. (2010). Psychometric properties of the parent and teacher versions of the Strengths and Difficulties Questionnaire for 4- to 12-year-olds: a review. Clinical Child and Family Psychology Review, 13, 254-274.
Tlale, J., et al. (2008). Mother to child HIV transmission in Botswanaanalysis of dried blood spot (DBS) results from the national PMTCT programme. Mexico City, Mexico: XVII International Conference on AIDS.

UNAIDS (2013). Global report: UNAIDS report on the global AIDS epidemic 2013. (http://www.unaids.org/en/media/unaids/ contentassets/documents/epidemiology/2013/gr2013/UNAIDS_ Global Report 2013 en.pdf, accessed December 2013)

UNAIDS and WHO (2013). Core Epidemiology Slides. Global summary of the AIDS epidemic, 2012 (http://www.unaids.org/en/media/ unaids/contentassets/documents/epidemiology/2013/gr2013/ 201309 epi core en.pdf, accessed, February 2014).

UNAIDS Country Progress Report on the Declaration of Commitment on HIV/AIDS. (2010) Report.(http://www.unaids.org/en/dataanalysis/ monitoringcountryprogress/2010progressreportssubmittedbycountries/ southafrica_2010_country_progress_report_en.pdf, accessed November, 2013)

US Food and Drug Administration. For Consumer. Timeline/ History. Retrieved from http://www.fda.gov/ForConsumers/ ByAudience/ForPatientAdvocates/HIVandAIDSActivities/ ucm117935.htm

WHO and UNICEF (2007). Guidance on global scale-up of the prevention of mother-to-child transmission of HIV. Towards universal access for women, infants and young children and eliminating HIV and AIDS among children. Geneva, World Health Organization (http://www.unicef.org/aids/files/PMTCT enWEBNov26.pdf, accessed October, 2013).

WHO, UNICEF, and World Bank. (2011). Global HIV/AIDS response. Epidemic update and health sector progress towards universal access. Progress Report 2011. Geneva, World Health Organization (http://www.who.int/hiv/pub/progress report2011/en/, accessed November 2013).

Wiener, L., \& Mellins, C. A. (2010). Psychosocial aspects of neurological impairment in children with aids. In H. E. Gendelman, I. P. Everall, H. S. Fox, I. Grant, S. Lipton, \& S. Swindells (Eds.), The neurology of AIDS. 2012 (3rd ed., pp. 925-942). Oxford, UK: Oxford University Press, Inc. 